\title{
Decade-long mitral valve surgery trends and rheumatic heart disease: a review of mitral valve surgery in a large Chinese cardiovascular center
}

\author{
Yuqing Jiao^, Tiange Luo, Xu Meng, Jiangang Wang \\ Cardiac Valve Center, Department of Cardiac Surgery, Beijing Anzhen Hospital, Capital Medical University, Beijing, China \\ Contributions: (I) Conception and design: All authors; (II) Administrative support: X Meng, J Wang; (III) Provision of study materials or patients: T \\ Luo, X Meng, J Wang; (IV) Collection and assembly of data: Y Jiao; (V) Data analysis and interpretation: Y Jiao, T Luo, J Wang; (VI) Manuscript \\ writing: All authors; (VII) Final approval of manuscript: All authors. \\ Correspondence to: Jiangang Wang. Cardiac Valve Center, Department of Cardiac Surgery, Beijing Anzhen Hospital, Capital Medical University, \\ Beijing 100029, China. Email: jiangangwang@ccmu.edu.cn.
}

Background Despite being one of the few chronic secondary heart diseases that can be prevented, current
epidemiological data on rheumatic heart disease (RHD) in China are unavailable. This study examined mitral
valve (MV) surgery trends in a large Chinese cardiovascular center over the last 10 years and provided insight
into the distribution of RHDs and their changes.

Methods: Medical records of patients who underwent cardiac surgery, MV surgery, and MV surgery for rheumatic MV (rMV) disease at Beijing Anzhen Hospital between January 2010 and December 2019 were retrospectively reviewed. Patients' demographic and clinical characteristics were statistically analyzed among age groups.

Results: Overall, 7,736 patients underwent rMV surgery and $87.5 \%$ were aged $40-70$ years. The proportion of patients aged $>60$ years increased annually $(\mathrm{P}<0.05)$, and the proportion of patients in all other age groups decreased. The proportion of patients with rMV diseases among those with cardiac or mitral valve diseases decreased each year, but the absolute number of patients with rMV disease remained stable. Approximately $90 \%$ of patients who underwent rMV surgery were from northern China. The incidence of rMV disease among patients with mitral valve disease moderately correlated with the per capita gross regional product (Per-GRP), an indicator of living standards ( $r=-0.517, \mathrm{P}<0.05)$.

Conclusions: RHD still exists in northern China and requires adequate resources for its management. The number of older patients with rMV disease presents a challenge for mitral valve surgery.

Keywords: Mitral insufficiency; mitral stenosis; rheumatic fever; rheumatic heart disease (RHD); socioeconomic status

Submitted Jul 21, 2021. Accepted for publication Nov 12, 2021.

doi: 10.21037/apm-21-2005

View this article at: https://dx.doi.org/10.21037/apm-21-2005

\section{Introduction}

Rheumatic heart disease (RHD) results from longterm cardiac damage due to severe or recurrent acute rheumatic fever (ARF), and occurs predominantly in low socioeconomic groups in developing countries where it still remains a public health problem $(1,2)$.

ARF is an autoimmune disease that occurs due to group A $\beta$-hemolytic streptococcal throat infections. Clinical manifestations of ARF include carditis, arthritis,

\footnotetext{
^ ORCID: 0000-0001-5704-5080.
} 
erythema marginatum, subcutaneous nodules, and chorea. All manifestations are transitory, except carditis, which leads to permanent heart valve damage $(3,4)$. Severe acute rheumatic valvulitis, accounting for approximately $10 \%$ of all ARFs (5), is characterized by mitral annular dilatation and chordal elongation, leading to mitral regurgitation (6). The hallmark chronic RHD lesion is mitral stenosis, characterized by commissural fusion, leaflet thickening, and alteration of the subvalvular apparatus (6,7). Studies have reported that the ARF onset age is usually between 5 and 15 years, and the incubation period from onset to clinical RHD symptom manifestation usually extends over $20-30$ years $(7,8)$. Moreover, $30-45 \%$ of ARF cases progress to RHD (9), and more than $60 \%$ of RHD cases are not associated with ARF history $(2,3)$.

Echocardiography is the traditional RHD screening method after identifying a heart murmur by auscultation in symptomatic patients. However, many studies have found that early echocardiographic intervention before abnormal auscultation improves the RHD detection rate by 3-10 times $(10,11)$. Auscultation-based screening has a low sensitivity, which may contribute to the low RHD detection rate. Thus, numerous patients with RHD have no confirmed history of ARF but show silent onset and progression (1).

Regarding high-risk populations, it is important to improve penicillin prophylaxis for both primary and secondary preventions, which separately reduce ARF incidence and ARF recurrence in people with a history of ARF or RHD. Therefore, early diagnosis and treatment of ARF or RHD in childhood or adolescence are essential to prevent chronic secondary cardiac disease $(5,12)$.

In previous reviews $(6,13)$, the ARF and RHD incidences were found to be high in China, with 7.5 million and 2.5 million cases, respectively. However, these results were mainly based on two surveys completed two and three decades ago (14-16). One survey was performed from 1992 to 1995 in five provinces and evaluated 220,000 school-aged students and kindergarten children aged 5-18 years for ARF and RHD $(14,15)$. The other was an RHD screening involving 9,124 participants aged $>18$ years in nine cities in 2001 and 2002 (16). However, based on clinical observations and reports $(17,18)$, over the past three decades in China, few children or adolescents have been clinically diagnosed with or suspected to have ARF or RHD, and few have undergone secondary prevention or long-term followup. This is paradoxical given the previously reported high numbers. Did the incidence of ARF and RHD decline actually in recent decades?

Given the absence of current epidemiological data, we examined the surgical trends for RHD in Beijing Anzhen Hospital over the last 10 years. Medical records retrieved from Beijing Anzhen Hospital, which is the second-largest cardiovascular center in China with $>10,000$ cardiovascular surgeries/year over the past decade, show that cardiac and valve surgeries in Anzhen Hospital accounted for approximately $5 \%$ of the corresponding surgeries in China (19). Most patients undergoing these surgeries were from northern China. Therefore, data from Beijing Anzhen Hospital could be considered a powerful window into the actual proportion of patients with heart disease that require surgery among the general population in northern China. We present the following article in accordance with the STROBE reporting checklist (available at https://apm. amegroups.com/article/view/10.21037/apm-21-2005/rc).

\section{Methods}

\section{Participants}

This study was a retrospective review of the data of all patients who underwent cardiac surgery at the Department of Adult Cardiology in Beijing Anzhen Hospital, Beijing, China, between January 2010 and December 2019. We identified patients who underwent mitral valve (MV) surgery; then, among these patients, we identified those who underwent surgery for rheumatic MV (rMV) disease.

rMV disease was diagnosed based on preoperative echocardiography and visible morphological changes during surgery (20,21). Pathological examination of the resected $M V$ was performed to confirm the diagnosis (21). An MV orifice area of $\leq 1.8 \mathrm{~cm}^{2}$ with or without $M V$ insufficiency was defined as stenosis or a mixed lesion, respectively. $M V$ insufficiency with an MV orifice area of $>1.8 \mathrm{~cm}^{2}$ was defined as isolated MV insufficiency (20).

\section{Measures and variables}

Age, sex, origin, and operation were collected. In the input of patients' place of origin, we refer to the native place, the place of birth, the place of registration, and the permanent address. After comprehensive analysis, the place of birth is the most likely to reflect the status of adolescents. As the incubation period from ARF onset to RHD clinical symptom manifestation usually extends over 20-30 years, the patients were grouped according to age: $\leq 30,31-40$, 
$41-50,51-60,61-70$, and $>70$ years.

As economic development is uneven in China and a low socioeconomic status is a principal risk factor for RHD, the provinces where patients resided and the per capita gross regional product (Per-GRP) of the province were recorded as indicators of living-standard (22). Compared to the existing data, GDP per capita is the closest macro-level variable.

This study was approved by the Ethics Review Committee of Beijing Anzhen Hospital, an affiliate of Capital Medical University, Beijing, China (No. 2021011X), and the requirement for individual consent for this retrospective analysis was waived. The study was conducted in accordance with the Declaration of Helsinki (as revised in 2013).

\section{Statistical analyses}

Statistical analyses were performed using IBM SPSS Statistics for Windows, version 22.0 (IBM Corp., Armonk, NY, USA). Count data are expressed as means \pm standard deviations and categorical data as frequencies. Statistical analysis was performed using the $t$-test or chi-square test to compare two groups, and one-way analysis of variance or the Kruskal-Wallis test was used to compare three or more groups. Pearson analysis was used for bivariate correlation of count data. Statistical significance was set at a $\mathrm{P}$ value of $<0.05$ (two-sided).

\section{Results}

\section{Baseline demographics and clinical parameters}

In total, 81,106 patients underwent cardiac surgery in our department within the study period. The patients' ages

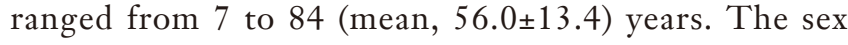
distribution was 1.9 to 1 (male to female). Of the 27,525 patients who underwent valve surgery, 16,348 underwent MV surgery and 7,736 underwent rMV surgery. The number of patients who underwent any cardiac or MV surgery increased annually, yet the number of patients who underwent rMV surgery remained stable. Correspondingly, the ratio of rMV surgeries to any type of cardiac or MV surgery decreased (Table 1 and Figure 1).

Over the entire period, the percentages of patients aged 40-70 years who underwent any cardiac, MV, or rMV surgery were $82.2 \%, 77.1 \%$, and $87.5 \%$, respectively. The average age of patients undergoing all three surgery types showed a trend of gradual increase (Table 1). The numbers of patients aged $>60$ years undergoing any cardiac, $M V$, or rMV surgery significantly increased annually, and the group aged 60-70 years was the largest for all three surgery types in the final year (Figure 2).

In contrast to cardiac and MV surgeries, the number of rMV surgeries trended downward in all age groups $<60$ years, especially in the 50-60-year group (36.2\%) (Figure 2). Significantly more male than female patients underwent any cardiac surgery $(1.9: 1 ; \mathrm{P}<0.05)$. However, more female than male patients underwent rMV surgery (0.4:1; $\mathrm{P}<0.05 ;$ Table 2).

\section{Patients' origins}

Overall, patients came from all over the country, but approximately $90 \%$ were from northern China. The provinces of origin remained nearly the same over time. For all surgery types, most patients came from the five northern provinces (in descending order): Hebei, Beijing, Inner Mongolia, Shandong, and Shanxi (for rMV surgery, more patients were from Shanxi than from Shandong). From these five provinces, $74.0 \%$ of patients underwent different cardiac surgeries, $70.0 \%$ underwent MV surgery, and $70.7 \%$ underwent rMV surgery (Table 2). Table 3 presents the provinces' Per-GRPs.

\section{Clinical characteristics of RHD}

Of the 7,736 patients who underwent rMV surgery, 7,352 had stenosis or stenosis combined with insufficiency, accounting for $95.4 \%$ of all patients with rMV. Of the 354 patients with isolated insufficiency (4.6\%), 16 were $<30$ years old, accounting for $15.5 \%$ of all patients in this age group. The insufficiency rate in patients aged $<30$ years was significantly higher than the insufficiency rate in the other age groups $(4.6-6.3 \%, \mathrm{P}<0.05)$.

Mechanical valve (mec-valve) replacement was the main surgical method for rMV disease over time $(5,707$ of 7,736, $73.7 \%$ ), but the rate declined over the observation period. The percentage of patients who underwent biological valve (bio-valve) replacement and MV repair increased over time. Bio-valve replacement surpassed mec-valve replacement and became the primary method in the $>60$ years age group in the final year (Table 4 and Figure 3). Among patients who underwent rMV surgery, 2,726 had combined aortic valve surgery $(35.2 \%)$, with no differences among the age groups ( $\mathrm{P}>0.05$, Table 5$)$. 
Table 1 The number and average age of patients underwent any cardiac, MV and rMV surgery in Beijing Anzhen Hospital from 2010 to 2019

\begin{tabular}{|c|c|c|c|c|c|c|}
\hline Year & Any cardiac (age, years) & MV (age, years) & rMV (age, years) & $\begin{array}{c}\text { MV/any cardiac } \\
(\%)\end{array}$ & $\begin{array}{c}\text { rMV/any cardiac } \\
(\%)\end{array}$ & $\begin{array}{c}\mathrm{rMV} / \mathrm{MV} \\
(\%)\end{array}$ \\
\hline 2010 & $6,372(54.0 \pm 15.0)$ & $1,238(52.2 \pm 11.9)$ & $763(52.8 \pm 10.0)$ & 19.4 & 12.0 & 61.6 \\
\hline 2012 & 7,132 (55.2 \pm 13.9$)$ & $1,344(53.3 \pm 11.7)$ & $774(53.8 \pm 10.0)$ & 18.8 & 10.9 & 57.6 \\
\hline 2015 & $8,535(56.5 \pm 12.6)$ & $1,697(54.6 \pm 11.6)$ & $797(55.8 \pm 9.6)$ & 19.9 & 9.3 & 47.0 \\
\hline 2016 & $8,687(56.6 \pm 12.5)$ & $1,689(55.1 \pm 11.8)$ & $751(55.9 \pm 9.5)$ & 19.4 & 8.6 & 44.5 \\
\hline 2017 & $8,685(56.6 \pm 12.5)$ & $1,823(55.7 \pm 11.6)$ & $726(55.7 \pm 9.9)$ & 21.0 & 8.4 & 39.8 \\
\hline$P_{1}$ for trend & 0.003 & 0.004 & 0.577 & & & \\
\hline$P_{2}$ for trend & 0.000 & 0.000 & 0.000 & & & \\
\hline
\end{tabular}

$\mathrm{P}_{1}$ for trend is calculated using the Chi-square test of tendency that reflects the overall rends of the number of patients in any cardiac, MV, or rMV surgery between the ten years. The number of patients who underwent any cardiac or MV surgery increased annually $\left(P_{1}\right.$ for trend <0.001); however, the number of patients who underwent rMV surgery remained stable $\left(P_{1}\right.$ for trend $\left.>0.05\right)$. $P_{2}$ for trend is calculated using the Polynomial of one-way ANOVA that reflects the overall rends of the average age of patients in any cardiac, MV, or rMV surgery between the ten years. The average age of patients in all the three groups increased annually $\left(P_{2}\right.$ for trend $\left.<0.001\right)$. MV, mitral valve; rMV, rheumatic mitral valve; ANOVA, analysis of variance.

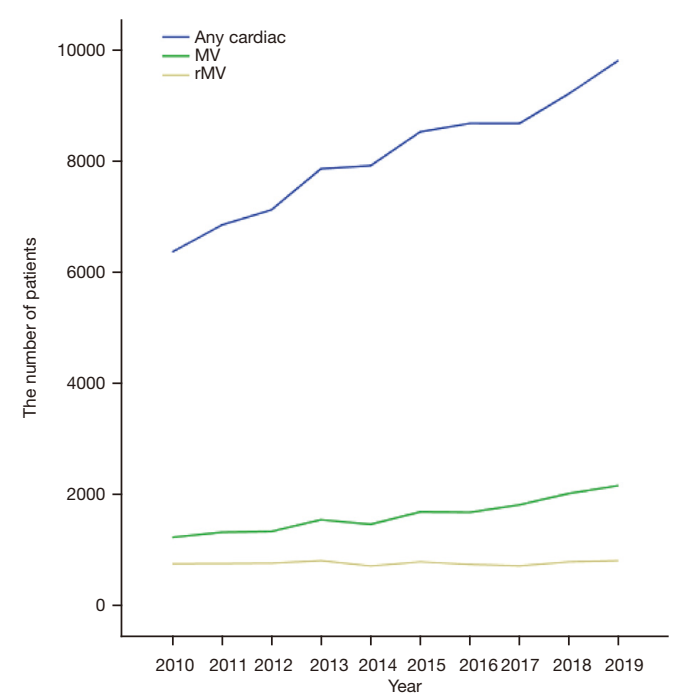

Figure 1 The number of patients underwent any cardiac, mitral valve (MV) and rheumatic mitral valve (rMV) surgery in Beijing Anzhen Hospital from 2010 to 2019.
Counting only rMV cases to assess the effect of the economic status on rMV was inaccurate owing to the increasing trend in the number of patients with $\mathrm{MV}$ disease. Thus, the proportional rMV trends among patients with MV disease were used to reflect the economic effect on rMV. Shanxi, the most undeveloped province of the five regions, had the highest rMV proportion and the smallest rMV proportional decrease over time (Figure 4). The rMV proportion among patients with $\mathrm{MV}$ disease moderately correlated with the Per-GRP $(\mathrm{r}=-0.517, \mathrm{P}<0.05$; Tables 3 and 6).

\section{Discussion}

This retrospective review analyzed the demographic and clinical characteristics of all patients who underwent any cardiac, MV, or rMV surgery in Beijing Anzhen Hospital over the last 10 years. Our results demonstrated that, among 

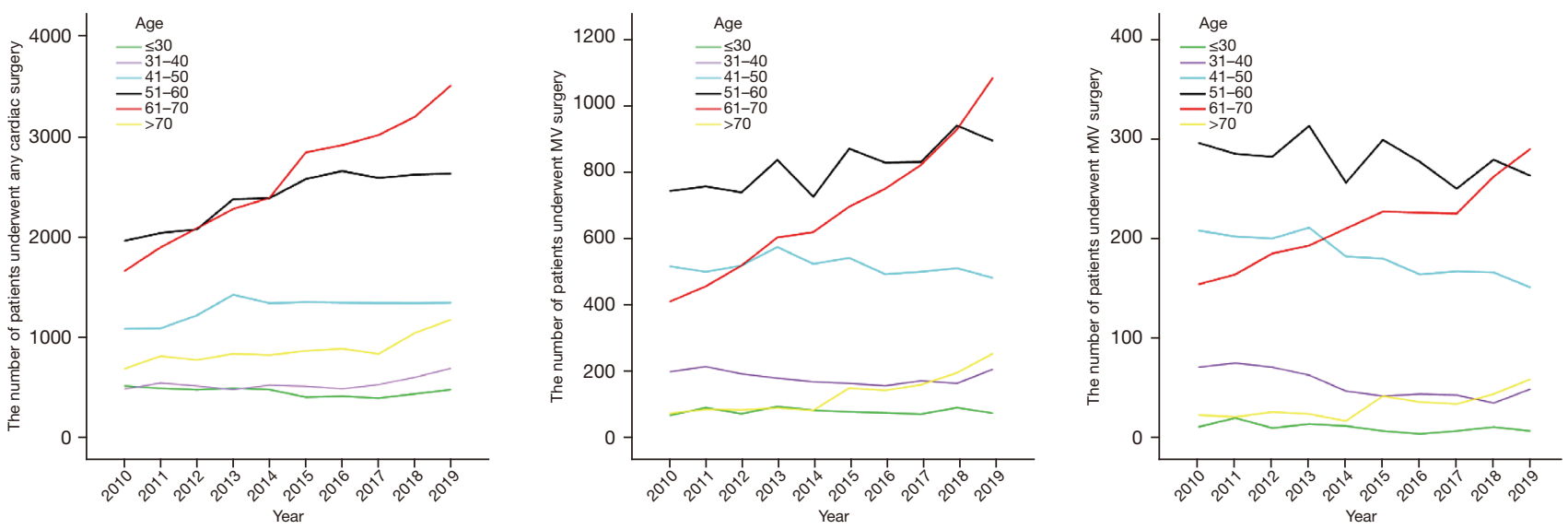

Figure 2 The number of patients in different age groups underwent any cardiac, mitral valve (MV) and rheumatic mitral valve (rMV) surgery in Anzhen Hospital from 2010 to 2019.

Table 2 The number of patients in different age groups, gender, and regions underwent any cardiac, MV, and rMV surgery in Beijing Anzhen Hospital from 2010 to 2019

\begin{tabular}{|c|c|c|c|c|}
\hline Characteristics & Subtypes & Any cardiac surgery, n (\%) & MV surgery, n (\%) & rMV surgery, n (\%) \\
\hline \multirow{5}{*}{ Age (years) } & $31-40$ & $5,340(6.6)$ & $1,260(7.7)$ & $540(7.0)$ \\
\hline & $41-50$ & $12,854(15.8)$ & 3,322 (20.3) & $1,831(23.7)$ \\
\hline & $51-60$ & $23,886(29.5)$ & $5,369(32.8)$ & $2,800(36.2)$ \\
\hline & $>70$ & $8,708(10.7)$ & $973(6.0)$ & $326(4.2)$ \\
\hline & Count & $81,106(100.0)$ & $16,348(100.0)$ & $7,736(100.0)$ \\
\hline \multirow[t]{2}{*}{ Gender } & Male & $53,444(65.9)$ & $7,811(47.8)$ & 2,314 (29.9) \\
\hline & Female & $27,662(34.1)$ & $8,537(52.2)$ & $5,422(70.1)$ \\
\hline \multirow{5}{*}{ Region } & Beijing & $17,472(21.5)$ & $2,846(17.4)$ & $1,267(16.4)$ \\
\hline & Inner Mongolia & 7,954 (9.8) & $1,660(10.2)$ & $904(11.7)$ \\
\hline & Shandong & $6,827(8.4)$ & $1,450(8.9)$ & $585(7.6)$ \\
\hline & Shanxi & $5,760(7.1)$ & $1,247(7.6)$ & $760(9.8)$ \\
\hline & Count & $60,052(74.0)$ & $11,439(70.0)$ & $5,472(70.7)$ \\
\hline
\end{tabular}

MV, mitral valve; rMV, rheumatic mitral valve.

all MV surgeries, the percentage of patients who underwent rMV surgery decreased but never fell below $35 \%$, yet the number of patients who underwent rMV surgery remained stable throughout the study period.

Generally, the MV is the most frequently damaged valve in RHD, and mitral stenosis increases over time as the disease progresses $(5,21)$. Aortic valve damage combines with MV damage in $20-25 \%$ of patients, becoming more common with increasing age $(3,5,23)$. Isolated aortic valve damage accounts for only $2 \%$ of RHD cases, usually in 
Table 3 Per capita gross regional product of the five provinces in the order of the number of patients (Chinese Yuan)

\begin{tabular}{|c|c|c|c|c|c|}
\hline Year & Beijing & Shandong & Inner Mongolia & Hebei & Shanxi \\
\hline 2011 & 82,658 & 47,335 & 57,974 & 33,969 & 31,357 \\
\hline 2012 & 87,475 & 51,768 & 64,886 & 36,584 & 33,628 \\
\hline 2013 & 94,648 & 56,885 & 67,836 & 38,908 & 34,984 \\
\hline 2015 & 106,497 & 64,168 & 71,101 & 40,255 & 34,919 \\
\hline 2016 & 118,198 & 68,733 & 72,064 & 43,062 & 35,532 \\
\hline 2017 & 128,994 & 72,807 & 63,764 & 45,387 & 42,060 \\
\hline 2018 & 140,211 & 76,267 & 68,302 & 47,772 & 45,328 \\
\hline
\end{tabular}

Table 4 The number of patients underwent different surgical procedures of rheumatic mitral valve in all age groups and in age groups over 60 years old in Anzhen Hospital from 2010 to 2019

\begin{tabular}{|c|c|c|c|c|c|c|}
\hline Year & \multicolumn{3}{|c|}{ Operation (all age groups) } & \multicolumn{3}{|c|}{ Operation (age groups over 60 years old) } \\
\hline 2010 & 708 & 44 & 11 & 134 & 40 & 3 \\
\hline 2011 & 695 & 49 & 23 & 139 & 43 & 3 \\
\hline 2012 & 639 & 112 & 23 & 131 & 75 & 5 \\
\hline 2014 & 558 & 87 & 79 & 137 & 69 & 21 \\
\hline 2015 & 608 & 129 & 60 & 140 & 107 & 22 \\
\hline 2016 & 519 & 138 & 94 & 120 & 117 & 25 \\
\hline 2017 & 447 & 150 & 129 & 106 & 115 & 38 \\
\hline Count & 5,707 & 1,174 & 855 & 1,266 & 926 & 270 \\
\hline
\end{tabular}

patients with acute rheumatic valvulitis $(5,12,24)$. Isolated tricuspid or pulmonary valve affection is rarely observed $(5,12,24)$. Therefore, surgery for rMV may represent surgery for RHD. The number of patients who underwent rMV surgery annually was constant in this study, suggesting that RHD persists in the population of northern China.

The percentage of patients aged $>60$ years undergoing cardiac surgery increased annually, especially for patients aged 60-70 years, which was the largest age group among patients undergoing rMV surgery in the final year of the study. Among patients aged $>60$ years, changes in the percentage of patients who underwent rMV surgery corresponded with that of patients who underwent any cardiac or MV surgery. However, in all age groups $<60$ years, the percentage of patients who underwent $\mathrm{rMV}$ surgery trended to reduce compared to that of patients who underwent any cardiac or MV surgery. In the first 9 years, rMV surgery was most common in the 50-60-year age group $(36.2 \%, \mathrm{P}<0.05)$. Comparing the percentage of older patients who underwent rMV surgery with the percentage 


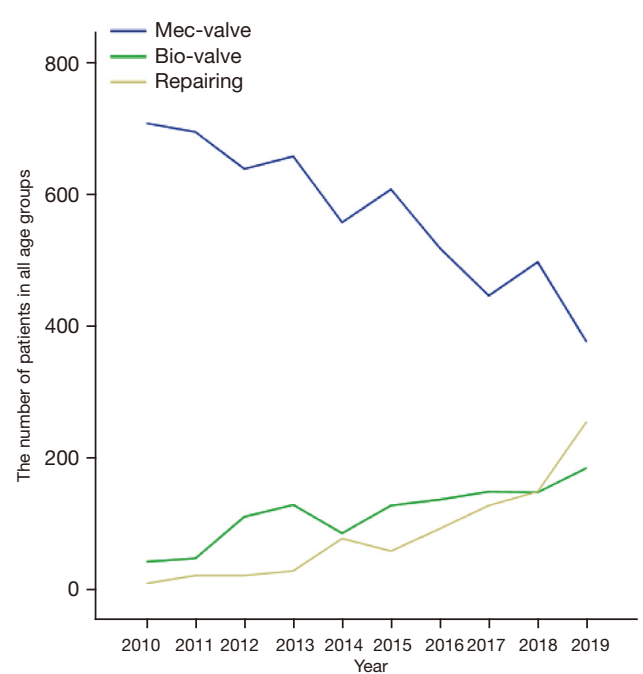

Year

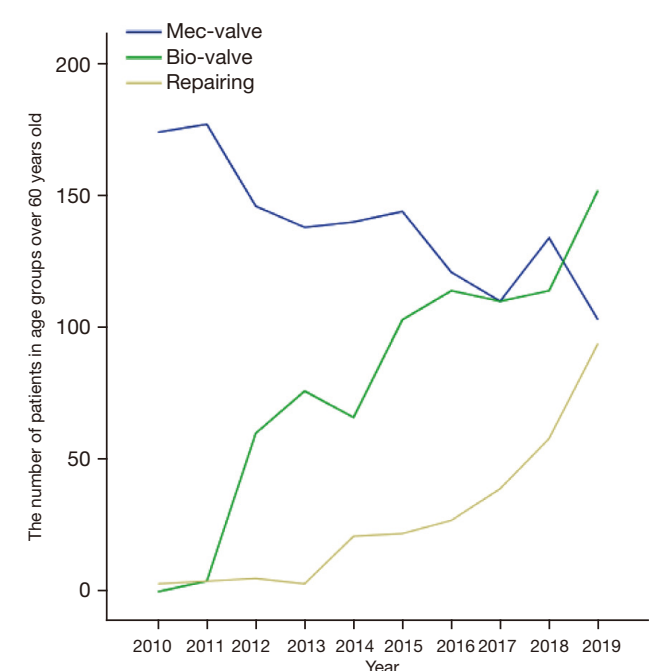

Year

Figure 3 The number of patients underwent different surgical procedures of rheumatic mitral valve in all age groups and in age groups over 60 years old in Anzhen Hospital from 2010 to 2019.

Table 5 The number of patients in different pathological changes of rheumatic valve in Anzhen Hospital from 2010 to 2019

\begin{tabular}{|c|c|c|c|c|c|c|}
\hline Age & \multicolumn{3}{|c|}{ Mitral valve } & \multicolumn{3}{|c|}{ Combined with aortic valve } \\
\hline$\leq 30$ & $87(84.5)$ & $16(15.5)$ & 103 & $70(68.0)$ & $33(32.0)$ & 103 \\
\hline $31-40$ & $506(93.7)$ & $34(6.3)$ & 540 & $354(65.6)$ & $186(34.4)$ & 540 \\
\hline $41-50$ & $1,751(95.6)$ & $80(4.4)$ & 1,831 & $1,141(62.3)$ & $690(37.7)$ & 1,831 \\
\hline $61-70$ & $2,044(95.7)$ & $92(4.3)$ & 2,136 & $1,419(66.4)$ & $717(33.6)$ & 2,136 \\
\hline$>70$ & 309 (94.8) & $17(5.2)$ & 326 & $223(68.4)$ & $103(31.6)$ & 326 \\
\hline Count & $7,382(95.4)$ & $354(4.6)$ & 7,736 & $5,010(64.8)$ & $2,726(35.2)$ & 7,736 \\
\hline
\end{tabular}

MS, mitral valve stenosis; MI, mitral valve insufficiency.

of those who underwent any cardiac or MV surgery suggested that there was a comparable and large number of patients who experienced ARF or RHD in the past.

China's economy has steadily developed over the last 30 years. Thus, the ARF incidence and RHD development, which are closely related to economic development, are theoretically expected to decrease (5). Further, the rate of older patients with RHD who experienced ARF before the current economic development started, is expected to increase. Our age-stratified analysis of patients with RHD assumed that the group of patients who experienced ARF decades ago reflected the current population situation, and their proportion among the population within their age bracket increased. For patients who previously experienced
ARF, old age and more serious rheumatic damage present a higher risk, creating a new challenge for MV surgery.

The current surgical methods for $\mathrm{rMV}$ disease include $M V$ replacement and MV repair. MV replacement is a welldeveloped procedure that includes mec-valve or bio-valve replacement. Our single-center data indicated that mecvalve replacement remained the dominant $\mathrm{rMV}$ surgical method, but its use is declining. This result reflects the increased use of bio-valve replacement, especially in patients aged $>60$ years. In this group, bio-valve replacement surpassed mec-valve replacement and was the primary surgical method in the final year of the study. Given the increasing popularity and evolution of interventional valve technologies (25), we foresee enormous potential for bio- 
valve replacement. The status following $M V$ repair more closely mimics the physiological state. Thus, MV repair could be more beneficial, although it is more challenging than valve replacement. The discussion on the best repair for $\mathrm{rMV}$ is ongoing $(20,26,27)$. Over the last 10 years, the number of MV repairs at Beijing Anzhen Hospital increased

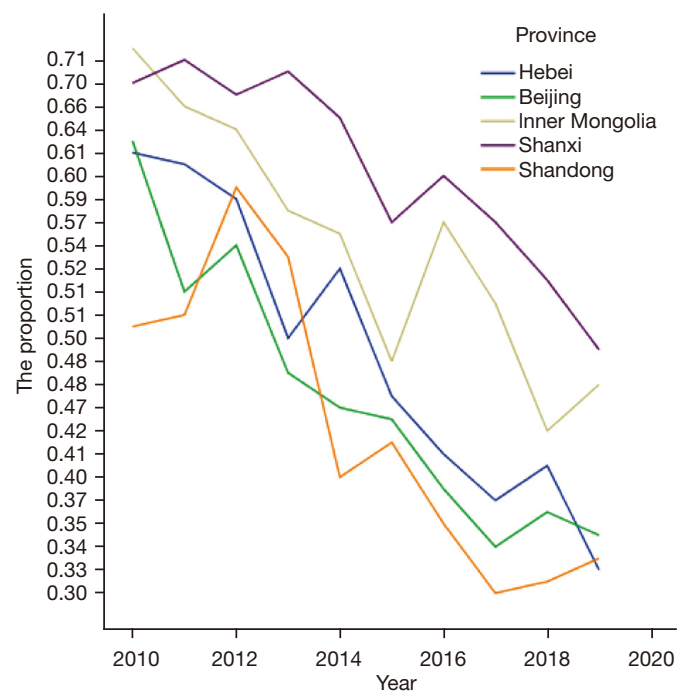

Figure 4 The proportion of rheumatic mitral valve (rMV) among mitral valve (MV) patients came from the top five provinces in Anzhen Hospital from 2010 to 2019. annually, and the results of the mid-term follow-up were satisfactory $(28,29)$. Therefore, patients with RHD aged $>60$ years in this study present new challenges regarding optimizing treatment, reducing surgical risk, and selecting valve repair or replacement.

In our study, MV stenosis was the dominant lesion (95.4\%), and combined with aortic stenosis (35.2\%), was more common than the incidence reported in the literature $(3,5,23)$. The average age of our patients was 54.9 years. These findings suggest that the RHD history in our cohort was longer than the duration previously described in the literature (30,31). We cannot offer statistics on ARF in this study because of incomplete ARF history data. However, based on our limited data, more than $70 \%$ of the patients with rMV had no history of ARF or recurrent throat infection, suggesting that they may have had a silent or undetected attack. In principle, except in early combined carditis, ARF and RHD are different stages of the same disease. Decade-long silent RHD might indicate neglected ARF in childhood or adolescence. Thus, considering the initially described paradoxical situation, a high RHD incidence is expected, yet low numbers of clinically diagnosed or suspected cases are reported. In addition, the economy significantly improved over the three most recent decades in China, and changes in the incidence and treatment of ARF and RHD might play a role in our results.

Table 6 The number and percentage of patients came from the top five provinces underwent rMV/MV surgery in Anzhen Hospital from 2010 to 2019

\begin{tabular}{|c|c|c|c|c|c|c|}
\hline \multirow{2}{*}{ Year } & \multicolumn{5}{|c|}{ Patients in different provinces (rMV/MV, \%) } & \multirow{2}{*}{ Count } \\
\hline & Hebei & Beijing & Inner Mongolia & Shanxi & Shandong & \\
\hline 2010 & $172 / 280(61.4 \%)$ & $170 / 276(61.6 \%)$ & $85 / 117(72.6 \%)$ & $77 / 110(70.0 \%)$ & 49/98 (50.0\%) & $553 / 881(62.8 \%)$ \\
\hline 2011 & $198 / 323(61.3 \%)$ & $141 / 276(51.1 \%)$ & $80 / 122(65.6 \%)$ & $84 / 118(71.2 \%)$ & $56 / 111(50.5 \%)$ & $559 / 950(58.8 \%)$ \\
\hline 2012 & $210 / 358(58.7 \%)$ & $124 / 230(53.9 \%)$ & $86 / 134(64.2 \%)$ & $72 / 107(67.3 \%)$ & $57 / 92(58.8 \%)$ & $549 / 926(59.3 \%)$ \\
\hline 2014 & $194 / 376(51.6 \%)$ & $110 / 235(46.8 \%)$ & $83 / 151(55.0 \%)$ & $87 / 135(64.4 \%)$ & $54 / 135(40.0 \%)$ & $528 / 1,032(51.2 \%)$ \\
\hline 2015 & $201 / 422(47.6 \%)$ & $133 / 287(46.3 \%)$ & $73 / 151(48.3 \%)$ & $83 / 146(56.8 \%)$ & $66 / 161(41.0 \%)$ & $556 / 1,167(47.6 \%)$ \\
\hline 2016 & $185 / 455$ (40.7\%) & 113/292 (38.7\%) & $100 / 176(56.8 \%)$ & 75/126 (59.5\%) & $51 / 147(34.7 \%)$ & $524 / 1,196(43.8 \%)$ \\
\hline 2017 & $182 / 490(37.1 \%)$ & 107/312 (34.3\%) & 95/187 (50.8\%) & $71 / 125(56.8 \%)$ & $52 / 171(30.4 \%)$ & $507 / 1,285(39.5 \%)$ \\
\hline Count & $1,956 / 4,235$ (46.2\%) & $1,267 / 2,846(44.5 \%)$ & $904 / 1,660(54.5 \%)$ & $760 / 1,247$ (60.9\%) & $585 / 1,450(40.3 \%)$ & $5,472 / 11,438(47.8 \%)$ \\
\hline
\end{tabular}

rMV, rheumatic mitral valve; MV, mitral valve. 
In this study, we introduced the Per-GRP as a livingstandard measure. According to the China Bureau of Statistics, the Per-GRPs of the five most reported provinces were ranked as Beijing, Shandong, Inner Mongolia, Hebei, and Shanxi, in this order. Shanxi, the most undeveloped province, had the highest $\mathrm{rMV}$ proportion among patients with $M V$ and the smallest proportional decrease in $\mathrm{rMV}$ among MV cases. Further, Pearson analysis suggested that the proportional $\mathrm{rMV}$ trend among patients with $\mathrm{MV}$ moderately correlated with the Per-GRP. As economic development is significantly unbalanced among regions in China, sufficient medical resources should be allocated per region to investigate the incidence and treatment of ARF and RHD.

\section{Study limitations}

This was a retrospective analysis at a single cardiovascular center over a limited observation period. Therefore, our results should be interpreted within these limitations. Additionally, economic development is uneven in China, and the population is large. Thus, it is not possible to conclude on the incidence of ARF or RHD in the entire country. Before data from updated epidemiological surveys are available, more pediatric and cardiovascular centers across the regions should pay attention to the frequency of $\mathrm{ARF}$ and RHD among their patients.

\section{Conclusions}

RHD still exists in northern China, and sufficient medical resources should be reserved for treatment. A large number of older patients experienced ARF or RHD before the start of socioeconomic development in China, affecting their living conditions and posing a new challenge for $\mathrm{MV}$ surgery.

\section{Acknowledgments}

We would like to thank Editage (www.editage.cn) for English language editing.

Funding: None.

\section{Footnote}

Reporting Checklist: The authors have completed the STROBE reporting checklist. Available at https://apm. amegroups.com/article/view/10.21037/apm-21-2005/rc
Data Sharing Statement: Available at https://apm.amegroups. com/article/view/10.21037/apm-21-2005/dss

Conflicts of Interest: All authors have completed the ICMJE uniform disclosure form (available at https://apm. amegroups.com/article/view/10.21037/apm-21-2005/coif). The authors have no conflicts of interest to declare.

Etbical Statement: The authors are accountable for all aspects of the work in ensuring that questions related to the accuracy or integrity of any part of the work are appropriately investigated and resolved. The study was approved by the Ethics Review Committee of Beijing Anzhen Hospital, an affiliate of Capital Medical University, Beijing, China (No. 2021011X), and individual consent for this retrospective analysis was waived. The study was conducted in accordance with the Declaration of Helsinki (as revised in 2013).

Open Access Statement: This is an Open Access article distributed in accordance with the Creative Commons Attribution-NonCommercial-NoDerivs 4.0 International License (CC BY-NC-ND 4.0), which permits the noncommercial replication and distribution of the article with the strict proviso that no changes or edits are made and the original work is properly cited (including links to both the formal publication through the relevant DOI and the license). See: https://creativecommons.org/licenses/by-nc-nd/4.0/.

\section{References}

1. Marijon E, Celermajer DS, Jouven X. Rheumatic Heart Disease - An Iceberg in Tropical Waters. N Engl J Med 2017;377:780-1.

2. Carapetis JR, Beaton A, Cunningham MW, et al. Acute rheumatic fever and rheumatic heart disease. Nat Rev Dis Primers 2016;2:15084.

3. Zühlke L, Engel ME, Karthikeyan G, et al. Characteristics, complications, and gaps in evidence-based interventions in rheumatic heart disease: the Global Rheumatic Heart Disease Registry (the REMEDY study). Eur Heart J 2015;36:1115-22a.

4. Tandon R, Sharma M, Chandrashekhar Y, et al. Revisiting the pathogenesis of rheumatic fever and carditis. Nat Rev Cardiol 2013;10:171-7.

5. Remenyi B, ElGuindy A, Smith SC Jr, et al. Valvular aspects of rheumatic heart disease. Lancet 2016;387:1335-46. 
6. Gewitz MH, Baltimore RS, Tani LY, et al. Revision of the Jones Criteria for the diagnosis of acute rheumatic fever in the era of Doppler echocardiography: a scientific statement from the American Heart Association. Circulation 2015;131:1806-18.

7. Horstkotte D, Niehues R, Strauer BE. Pathomorphological aspects, aetiology and natural history of acquired mitral valve stenosis. Eur Heart J 1991;12 Suppl B:55-60.

8. Carapetis JR, McDonald M, Wilson NJ. Acute rheumatic fever. Lancet 2005;366:155-68.

9. Cilliers AM. Rheumatic fever and its management. BMJ 2006;333:1153-6.

10. Marijon E, Ou P, Celermajer DS, et al. Prevalence of rheumatic heart disease detected by echocardiographic screening. N Engl J Med 2007;357:470-6.

11. Noubiap JJ, Agbor VN, Bigna JJ, et al. Prevalence and progression of rheumatic heart disease: a global systematic review and meta-analysis of population-based echocardiographic studies. Sci Rep 2019;9:17022.

12. Reményi B, Wilson N, Steer A, et al. World Heart Federation criteria for echocardiographic diagnosis of rheumatic heart disease--an evidence-based guideline. Nat Rev Cardiol 2012;9:297-309.

13. Watkins DA, Johnson CO, Colquhoun SM, et al. Global, Regional, and National Burden of Rheumatic Heart Disease, 1990-2015. N Engl J Med 2017;377:713-22.

14. Huang ZD, Rao XX, Cen RC, et al. An updated epidemiologic survey of acute rheumatic fever among school-age children in China. Chin J Cardiol 1998;26:94-7.

15. Rao XX, Huang ZD, Cen RC, et al. An updated epidemiologic status of rheumatic heart disease in China - a survey report on rheumatic heart disease for the national eighth five - year key project of rheumatic fever investigation. Chin J Cardiol 1998;26:98-100.

16. Zhimin W, Yubao Z, Lei S, et al. Prevalence of chronic rheumatic heart disease in Chinese adults. Int J Cardiol 2006;107:356-9.

17. Abouzeid M, Katzenellenbogen J, Wyber R, et al. Rheumatic heart disease across the Western Pacific: not just a Pacific Island problem. Heart Asia 2017;9:e010948.

18. Lu H, Pan WZ, Wan Q, et al. Trends in the prevalence of heart diseases over a ten-year period from single-center observations based on a large echocardiographic database. J Zhejiang Univ Sci B 2016;17:54-9.

19. Chinese Society of Extracorporeal Circulation. White book of Chinese cardiovascular surgery and extracorporeal circulation in 2019. Chin J ECC 2020;18:193-6.

20. Otto CM, Nishimura RA, Bonow RO, et al. 2020 ACC/
AHA Guideline for the Management of Patients With Valvular Heart Disease: A Report of the American College of Cardiology/American Heart Association Joint Committee on Clinical Practice Guidelines. Circulation 2021;143:e72-e227.

21. Chandrashekhar Y, Westaby S, Narula J. Mitral stenosis. Lancet 2009;374:1271-83.

22. National bureau of statistics. China statistical yearbook. Available online: http://www.stats.gov.cn/tjsj/ndsj/

23. Kumar RK, Tandon R. Rheumatic fever \& rheumatic heart disease: the last 50 years. Indian J Med Res 2013;137:643-58.

24. Marijon E, Mirabel M, Celermajer DS, et al. Rheumatic heart disease. Lancet 2012;379:953-64.

25. Kamioka N, Babaliaros V, Morse MA, et al. Comparison of Clinical and Echocardiographic Outcomes After Surgical Redo Mitral Valve Replacement and Transcatheter Mitral Valve-in-Valve Therapy. JACC Cardiovasc Interv 2018;11:1131-8.

26. Antunes MJ. Repair for rheumatic mitral valve disease. The controversy goes on! Heart 2018;104:796-7.

27. Vassileva CM, Mishkel G, McNeely C, et al. Long-term survival of patients undergoing mitral valve repair and replacement: a longitudinal analysis of Medicare fee-forservice beneficiaries. Circulation 2013;127:1870-6.

28. Jiao Y, Luo T, Zhang H, et al. Repair versus replacement of mitral valves in cases of severe rheumatic mitral stenosis: midterm clinical outcomes. J Thorac Dis 2019;11:3951-61.

29. Tiange L, Xu M. Repair Strategies Based on Pathological Characteristics of the Rheumatic Mitral Valve in Chinese Patients. Heart Lung Circ 2018;27:856-63.

30. Yau TM, El-Ghoneimi YA, Armstrong S, et al. Mitral valve repair and replacement for rheumatic disease. J Thorac Cardiovasc Surg 2000;119:53-60.

31. Saurav A, Alla VM, Kaushik M, et al. Outcomes of mitral valve repair compared with replacement in patients undergoing concomitant aortic valve surgery: a metaanalysis of observational studies. Eur J Cardiothorac Surg 2015;48:347-53.

Cite this article as: Jiao Y, Luo T, Meng X, Wang J. Decadelong mitral valve surgery trends and rheumatic heart disease: a review of mitral valve surgery in a large Chinese cardiovascular center. Ann Palliat Med 2022;11(4):1160-1169. doi: 10.21037/apm21-2005 